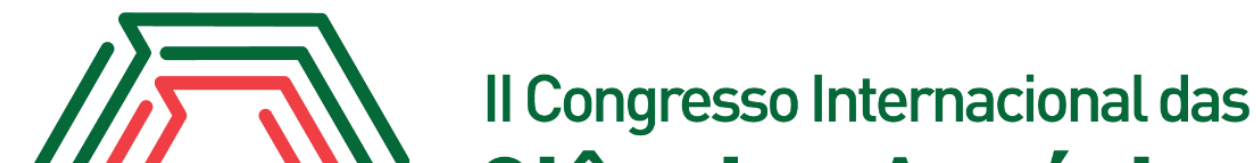 Ciências Agrárias COINTER - PDVAgro 2017
}

\section{QUALIDADE MICROBIOLÓGICA DE LINGUIÇA DE ATUM UTILIZANDO INULINA}

\author{
Apresentação: Pôster
}

Andréia Amanda Bezerra Jácome ${ }^{1}$; Maria Rociene Abrantes ${ }^{2} ; J^{2} a n$ Berg Alves da Silva ${ }^{3}$

\section{Introdução}

O pescado é um alimento de elevado valor biológico e fácil digestibilidade. Ao ser utilizado como matéria-prima pela indústria de beneficiamento, é necessário que sejam utilizados processos tecnológicos adequados para manutenção da estabilidade físico-química, sensorial e microbiológica (BERTULLO, 1975).

As análises microbiológicas de alimentos são usadas na avaliação retrospectiva da qualidade microbiológica ou para avaliar a "segurança" daquilo que consumimos. A segurança quanto ao pescado é de suma importância, já que as doenças transmitidas por alimento acontecem em decorrência da falta de cuidados e de controle desde o momento de aquisição da matéria-prima até o seu processamento (HUSS, 1997; MARQUES et al., 2009).

Condições sanitárias adequadas no processamento do pescado são essenciais para que o alimento ingerido seja seguro. Para manter a qualidade sensorial e microbiológica bem como aumentar a vida de prateleira do pescado e seus produtos é extremamente importante conservá-los em condições de higiene e temperatura próxima a $0^{\circ} \mathrm{C}$ (POLI et al., 2006; ÁLVARES et al., 2008).

O objetivo desse trabalho foi ver a viabilidade da produção de um embutido do tipo linguiça, usando o atum como matéria-prima e substituindo a gordura animal (toucinho) por inulina, e avaliar a qualidade microbiológica desse produto.

\section{Fundamentação Teórica}

A busca por uma alimentação mais saudável tem feito a procura por pescado aumentar. O

\footnotetext{
${ }^{1}$ Pós-graduação em Produção Animal, Universidade Federal Rural do Semi-Árido, amandabjacome@gmail.com

2 Doutorado, Universidade Federal Rural do Semi-Árido,rocienevet3@hotmail.com

${ }^{3}$ Doutorado, Universidade Federal Rural do Semi-Árido, jeanberg@ufersa.edu.br
} 
atum é uma excelente fonte de proteínas de alto valor biológico, vitaminas e minerais e possui uma baixa concentração em gorduras saturadas e uma elevada concentração de gorduras poliinsaturadas (ômega 3), que trazem benefícios a saúde humana (VALA, 2016).

Apesar de existirem várias formas de processamento para agregar valor ao pescado, sua comercialização é feita em sua maior parte com a peça inteira resfriada ou congelada (LARA et al., 2007). Os peixes podem ser submetidos a uma série de processamentos diferentes, o que permite a obtenção de uma ampla gama de gostos e apresentações, o que torna esta matéria-prima uma das mais versáteis "commodities" alimentícias (FAO, 2007).

O incremento do valor nutricional de carnes e produtos cárneos pode ser obtido através do da reformulação dos produtos, adicionando ingredientes com propriedades funcionais (ZHANG et al., 2010). Um exemplo de ingrediente funcional é a inulina, que é uma fibra alimentar, e é considera um prebiótico por estimular seletivamente a proliferação ou atividade de bactérias benéficas desejáveis no intestino grosso. (ROBERFROID, 2007).

Os produtos pesqueiros quando não obtidos e/ou armazenados em condições higiênicas adequadas podem ser disseminadores de agentes patogênicos como vírus, bactérias e biotoxinas, responsáveis por causar diversas enfermidades na população. As infecções humanas causadas por patógenos transmitidos a partir de pescado manipulado em condições sanitárias inadequadas são bastante comuns (MARTINS et al., 2002).

\section{Metodologia}

O trabalho realizado trata-se de uma pesquisa qualitativa, experimental. De início, foram elaboradas formulações diferentes para linguiça utilizando atum como matéria-prima, sendo a primeira (LA) o controle, usando apenas atum na sua elaboração, a segunda (LAT) com toucinho, e a terceira (LAI) com inulina, substituindo o toucinho. Os demais ingredientes foram sal, pimenta do reino, orégano e alho, todos com a mesma proporção (Figura 1). O processamento da linguiça foi realizado no Laboratório de Análises Instrumentais e Sensoriais (LANIS), seguindo o fluxograma abaixo, em seguida as amostras foram congeladas a $-4^{\circ} \mathrm{C}$ durante 15 dias. 
Figura 1. Fluxograma das etapas do processamento da linguiça de atum. Fonte: Própria.

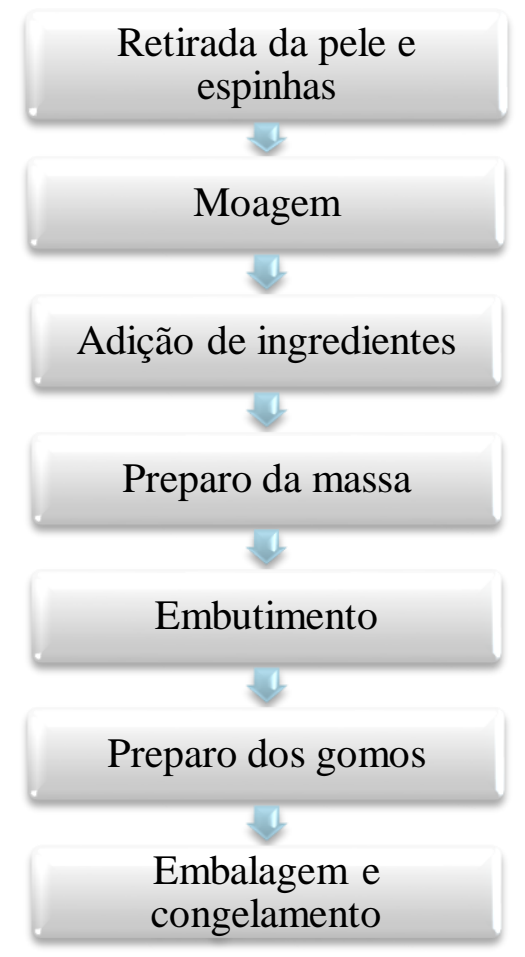

Após o período de congelamento, foram feitasas análises de determinação do Número Mais Provável (NMP) de Coliformes a 36 e $45^{\circ} \mathrm{C}$, contagem de Staphylococcus coagulase positiva e pesquisa de Salmonella spp., de acordo com a legislação brasileira (BRASIL, 2003), todas realizadas no Laboratório de Inspeção de Produtos de Origem Animal (LIPOA).

\section{Resultados e Discussões}

Os resultados obtidos nas análises microbiológicas das três formulações de linguiça de atum estão expressos na tabela abaixo.

Tabela 1: Análise microbiológica de diferentes formulações de linguiça de atum, 2017. Fonte: Própria

\begin{tabular}{lcccc}
\hline \multicolumn{1}{c}{ MICRORGANISMOS } & LA & LAT & LAI & LIMITE RDC N $\mathbf{N}^{\circ} \mathbf{2}$ \\
\hline Coliformes a $35^{\circ} \mathrm{C}(\mathrm{NMP} / \mathrm{g})$ & $4,3 \times 10^{1}$ & $0,92 \times 10^{1}$ & $1,50 \times 10^{2}$ & - \\
Coliformes a $45^{\circ} \mathrm{C}(\mathrm{NMP} / \mathrm{g})$ & $4,3 \times 10^{1}$ & $0,92 \times 10^{1}$ & $2,0 \times 10^{1}$ & $10^{3}$ \\
Est. Coag. Pos. (UFC) & - & $1,75 \times 10^{2}$ & $4,9 \times 10^{1}$ & $10^{3}$ \\
Salmonellaspp. & AUS & AUS & AUS & AUS \\
\hline
\end{tabular}

A RDC n 12 da Agência Nacional de Vigilância Sanitária (ANVISA) não estabelece 
limites específicos para embutidos a base de pescado, mas para os produtos à base de pescado resfriados ou congelados, as normas são: máximo de $10^{3} \mathrm{NMP} / \mathrm{g}$ para Coliformes a $45^{\circ}$, de $10^{3}$ UFC/g para estafilococos coagulase positiva e ausência de Salmonella (BRASIL, 2001).

Houve ocorrência de Staphylococcus coagulase positiva nas formulações LAT e LAI, diferindo de SLEDER 2015, que não detectou a presença desse microrganismo em diferentes formulações de linguiça de tambaqui. A contaminação por essa bactéria pode se dar de várias formas, como pela água do ambiente ou pela manipulação, já que este é um dos principais microrganismos associados à manipulação humana, por estar presente na cavidade nasal, em cortes na pele e até mesmo nos cabelos.

As análises mostraram ausência de Salmonella, resultado também encontrado por SLEDER 2015, e que cumpre com as exigências da Legislação, que impõe ausência desse contaminante em alimentos. Os dados obtidos para Coliformes a $35^{\circ}$ e a $45^{\circ} \mathrm{C}$ foram inferiores aos encontrados por MARQUES et al. 2014 para linguiça de tilápia do Nilo.

\section{Conclusões}

É possível a elaboração de um embutido do tipo linguiça a base de atum utilizando inulina como substituto ao toucinho, aumentando a gama de produtos a base de pescado, estimulando assim o consumo desse alimento. Apesar de ser uma proteína de fácil deterioração, a linguiça de atum mostrou boa qualidade microbiológica quando armazenada sob congelamento, seguindo os limites estipulados pela legislação vigente.

\section{Referências}

ÀLVARES, P.P.; MARTINS, L.; BORGHOFF, T. et al. Análise das características higiênico sanitárias e microbiológicas de pescado comercializado na grande São Paulo. Revista Higiene Alimentar, v.22, n.161, p.88-93, 2008.

BERTULLO VH. Tecnologia de los productos y subproductos de pescados, moluscos y crustáceos. $1^{a}$ ed. Buenos Aires: Editorial Hemisfério Sur; 1975

FAO - Food and Agricultural Organization of the United Nations. The state of world fisheries and aquaculture 2006 (SOFIA). Rome: FAO, 2007. 180p.

HUSS. Garantia de qualidade dos produtos da pesca. (FAO Documento Técnico sobre pescas, 334). Roma: FAO; 1997. 
LARA, J. A. F.; GARBELINI, J. S.; DELBEM, A. C. B. Tecnologias para a agroindústria: processamento artesanal do pescado do pantanal. Corumbá: Embrapa Pantanal, 2007. 5p.

Marques CO, Seabre LMJ, Damasceno KSFSC. Qualidade microbiológica de produtos a base de sardinha (Opisthonema oglium). Hig Aliment. 2009:23(174/175):99-104.

MARQUES, L. F. et al. Avaliação da qualidade de linguiça de Tilápia do Nilo (Oreochromis niloticus) Revista Semiárido De Visu, v.2, n.1, p.3-10, 2012.

MARTINS, C.V.B.; VAZ S.K., MINOZZO, M.G. Aspectos sanitários de pescados comercializados em "pesque-pagues" de Toledo (PR). Revista Higiene Alimentar, v.16, n.98, p.51-56, 2002.

POLI, B.M., MESSINI, A., PARISI, G. et al. Sensory, physical, chemical and microbiological changes in European sea bass (D. labrax) fillets packed under modified atmosphere/air or prepared from whole fish stored in ice. International Journal of Food Science and Technology, v.41, p.444454, 2006.

ROBERFROID, M. B. Prebiotics: the concept revisited. Journal of Nutrition, v. 37, p. 830-837, 2007.

SLEDER, F. Desenvolvimento e caracterização de linguiça frescal de Tambaqui (Colossoma macropomum). Dissertação apresentada para obtenção do título de mestre em Ciência Animal pela Universidade Federal de Mato Grosso (UFMG). Cuiabá, 2015.

VALA, M. O. Aplicação de revestimentos edíveis à base de subprodutos da indústria do pescado na preservação de atum fresco. Dissertação para obtenção do Grau de Mestre em Gestão da Qualidade e Segurança Alimentar pela IPL, Peniche-Portugal, 2016. Disponivel em https://iconline.ipleiria.pt/bitstream/10400.8/2281/1/tese_Milene_Vala.pdf acesso em 07 de junho de 2017.

ZHANG, W.; XIAO, S.; SAMARAWEERA, H.; LEE, E. J.; AHN, D. U. Improving functional value of meat products. Meat Science, v. 86, p.15-31, 2010. 